\title{
After-school care and parents' labor supply
}

\author{
Christina Felfe, Michael Lechner, and Petra Thiemann ${ }^{1}$
}

Date this version was printed: 22 June 2016

\begin{abstract}
Does the provision of after-school care promote maternal employment and thus help to foster gender equality in labor supply? We address this question by exploiting variation in cantonal (state) regulations of after-school care provision in Switzerland. To establish exogeneity of cantonal regulations with respect to employment opportunities and preferences of the population, we restrict our analysis to confined regions along cantonal borders. While no impact of the after-school care provision on parental employment exists overall, we find a positive impact on the full-time employment of mothers.
\end{abstract}

Keywords: Childcare, parental labor supply, instrumental variable method

JEL classification: J13, J22, C14

\section{Address for correspondence:}

Christina Felfe, Swiss Institute for Empirical Economic Research (SEW), University of St. Gallen, Varnbüelstrasse 14, CH-9000 St. Gallen, Switzerland, christina.felfe@unisg.ch, www.sew.unisg.ch/felfe.

Michael Lechner, Swiss Institute for Empirical Economic Research (SEW), University of St. Gallen, Varnbüelstrasse 14, CH-9000 St. Gallen, Switzerland, Michael.Lechner@unisg.ch, www.michael-lechner.eu.

Petra Thiemann, USC Dornsife Institute for New Economic Thinking, Department of Economics, University of Southern California, 3620 S Vermont Ave, Los Angeles, CA 90089, USA, petra.thiemann@usc.edu,www.petrathiemann.com.

1 Christina Felfe is also affiliated with CESIfo, Munich. Michael Lechner is also affiliated with CEPR, London, CESIfo, Munich, IAB, Nuremberg, and IZA, Bonn. This project received financial support from the Swiss National Science Foundation (SNF-NFP60 grant \# 406040-129248). We thank Infras, Zurich, for the provision of the data on childcare availability in Switzerland, and Massimo Mannino and Mattia Simion for valuable research assistance. A previous version of the paper was presented at the University of St. Gallen and at the All-California Labor Economics Conference at UC Berkeley. We thank participants, in particular Eva Deuchert and Jochen Mankart, and three anonymous referees for their helpful comments and suggestions. The usual disclaimer applies. 


\section{Introduction}

Although the participation of mothers in the labor market increased strongly during the $21^{\text {st }}$ century, a substantial gender gap in work hours of mothers and fathers remains. In 2009 , the average employment rate among women with children under the age of 15 amounted to $66 \%$ in OECD countries (OECD Family Database, 2012). Only a fraction of these women, however, worked full-time (45\%); $26 \%$ of these women worked $50-90 \%$ (34 days per week), and $29 \%$ worked less than $50 \%$. In contrast, a large majority of men with children under the age of 15 worked full-time (78\%). These gender differences partly arise from differential childcare responsibilities within families (OECD, 2001).

This paper provides empirical evidence on the effects of after-school care provision as a policy to promote mothers' employment and to foster gender equality in labor supply. Many developed countries currently expand the public ${ }^{2}$ supply of all-day schools and afterschool care, given the existing evidence on the negative consequences of reducing hours of work for female career opportunities (Waldfogel, 1997; Bratti, Bono, \& Vuri, 2004; Felfe, 2012). In addition to gender equality arguments, these policies follow at least two other justifications. First, individuals do not account for the possible public returns of their labor supply. They might thus undersupply labor from a social perspective, especially when childcare costs are high. Second, after-school care facilities face, in general, high set-up

We use the term "public" childcare interchangeably with "publicly regulated" childcare. In other words, public childcare slots do not necessarily need to be publicly financed. For details on the regulation and financing scheme of public childcare in Switzerland, the country under study, see Section 2. 
costs, which hamper market entry for private providers. By contrast, public providers may enter more easily and can save costs by using existing public infrastructure, like schools, for setting up childcare facilities. ${ }^{3}$ Yet, there is little evidence on the impact of after-school care on parental labor supply.

Identifying a causal effect of the after-school care provision on parents' labor supply is challenging since availability of after-school care is likely related to parental preferences to work and municipalities' efforts to attract additional long-term taxpayers (i.e. highly educated young workers). To establish a causal effect, we exploit legal differences in after-school care enforcement at the cantonal (state) level in Switzerland. Importantly, our analysis concentrates on narrowly defined areas along cantonal borders, which are homogenous in employment opportunities and preferences for after-school care provision. This regional restriction allows us to argue that cantonal regulations of childcare supply shift the childcare availability in a municipality, but are unrelated to parents' labor supply for reasons other than childcare availability. In other words, cantonal regulations serve as an instrumental variable for the after-school care provision.

We combine individual-level data from the 2010 Swiss Census with municipalitylevel data on the after-school care provision to implement this instrumental variable strategy. We find that an expansion of after-school care slots does not change the share of

In addition, Blau and Currie (2006) mention information asymmetries about the quality of childcare as a rationale for public intervention. This argument relates directly to a further motivation for public intervention: high-quality childcare may have direct consequences for the development of the children taken care of. For a recent overview of the consequences of childcare on child development, see Felfe (2015). 
working parents (extensive margin). Nevertheless, an expansion of after-school care slots does stimulate increases in maternal work hours (intensive margin): Each additional afterschool care slot encourages one more mother to boost her work hours to full-time. We do not find a comparable effect for fathers. Our results are robust to a series of robustness checks, including a difference-in-differences specification, which accounts for potentially unobserved differences between cantons prior to the enforcement of the after-school care provision. In addition, we estimate a series of specifications that allow the effects of the after-school care provision on parental labor supply to differ across local labor markets.

This paper relates to a broad literature that analyzes the consequences of the childcare provision for mothers' labor supply. Most studies focus on the impact of childcare for preschool-aged kids on the mothers of these children. A first set of studies identifies positive effects of the childcare provision on maternal employment. These studies either rely on regional and time variation in supply (Berlinski \& Galiani, 2007; Geyer, Haan, \& Wrohlich, 2015; Nollenberger \& Rodriguez-Planas, 2015; Schlosser, 2011), or on the introduction of a price subsidy for public care (Baker, Gruber, \& Milligan, 2008; Lefebvre \& Merrigan, 2008). In contrast to these studies, however, a second body of research finds that maternal labor supply on average does not react to increases in childcare availability. Only subgroups of mothers, such as single mothers or mothers living in disadvantaged areas, react positively to an increase in public childcare (Cascio, 2009; Fitzpatrick, 2010; Goux \& Maurin, 2010; Havnes \& Mogstad, 2011). Reasons for the lack of consensus in this literature may relate to different methodological approaches as well as 
to differences in the institutional setting - the initial level of childcare supply and/or maternal employment, for example.

To the best of our knowledge, evidence on the impact of providing care for older schoolchildren on maternal employment is scarce. ${ }^{4}$ In fact, we are aware of only one study that focuses on the effects of childcare for schoolchildren (Lundin, Mörk, \& Öckert, 2008). The authors evaluate the impact of a price reduction of care for children between the age of zero and nine in Sweden at a time when overall childcare coverage was already high $(80 \%)$. Their results reveal positive effects on overall maternal employment of subsidized care for preschool children. Yet, the effects are negligible for mothers of older children.

Our study contributes to this literature in at least three ways. First, we evaluate the impact of an expansion of the public care provision for schoolchildren in a context of low initial levels; in Switzerland in 2010, the coverage rate (available slots per children in the age of 4-12) was on average about $9 \%$. Thus, if levels have an impact on the magnitude of the effects, our results might differ from those of Lundin, Mörk, and Öckert (2008). This may particularly be the case if there is excess demand for public care. Second, we also consider the intensive margin, a margin that is relevant for female career opportunities.

4 A special section of a recent issue of Labour Economics (Volume 36, October 2015), devoted to the impact of childcare on maternal employment, highlights this fact: While six articles discuss the effectiveness of childcare available to preschool children, no article sheds light on the relevance of augmenting the hours of care provided by mandatory schooling by increasing the supply of after-school care. 
Finally, we also focus on paternal employment. Thus, the analysis sheds light on whether after-school care improves gender equality in labor supply.

The paper proceeds as follows. The next section provides an overview of the afterschool care system in Switzerland and the respective cantonal regulations. Section 3 discusses the empirical framework and underlying identification assumptions. Section 4 describes the data, and Section 5 shows the results and a series of robustness checks. Section 6 concludes.

\section{Institutional background: After-school care in Switzerland}

In Switzerland, the labor market attachment of parents with schoolchildren (ages 4 to 12 ) strongly differs by gender. In only $11 \%$ of families with schoolchildren do both parents work full-time; in $47 \%$ of families with schoolchildren, the mother works part-time and the father works full-time; and in $28 \%$ of families with schoolchildren, the mother does not work while the father works full-time. ${ }^{5}$ Hence, in most families the mother takes care of the children after the school day ends. In families where both parents work full-time, the common care arrangement is public or private after-school care.

What does a typical after-school care institution look like? After-school care services usually operate until 6 p.m. and serve lunch as well as an afternoon snack. Children

These numbers are based on the Swiss Structural Survey 2010. The remaining families (14\%) exhibit any other pattern, i.e. no parent is working or the family consists of only one parent and children. 
are cared for in groups of up to 22 children with at least two teachers, one of whom must be certified by the cantonal school authority. The care arrangement is thus professional and geared towards school-aged children. At least two rooms must be available per group so that the children have sufficient space to do their homework, rest, play, and move. Furthermore, an appropriate outdoor space must be nearby. In this way, after-school care offers supervision and support with homework as well as opportunities for children to play and participate in physical activities.

The fee for an unsubsidized slot amounts to CHF 40 (USD 40) per day on average, but most institutions offer subsidized slots. Yet, the total number of subsidized slots is severely rationed. Subsidies are income-dependent and only available in the municipality of residence. ${ }^{6}$ In principle, families can apply for an unsubsidized slot in an after-school care facility outside of their municipality of residence, yet it is unlikely that anyone would do so since distance to the school building - whose location is tied to the municipality of residence - is important when parents work full-time.

The municipalities are in charge of providing after-school care. Therefore, coverage rates do not only vary across cantons but also within cantons (see Figure 1 and 2 ). ${ }^{7}$ For

6 So far, no reliable data on the availability or the amount of public subsidies exists. Therefore, our study can only provide estimates for the impact of the availability of childcare slots without estimates on the respective price elasticity.

7 This data stems from a recent data collection by Infras, Zurich, and the Swiss Institute of Empirical Economic Research at the University of St. Gallen. It facilitates a national overview of childcare availability at the municipality level for the year 2010. For details, please refer to Felfe, Lechner, Iten, Schwab, Stern, and Thiemann (2013). 
instance, in the canton of Zurich, $1 \%$ of all schoolchildren live in a municipality with no after-school care slots while $54 \%$ of schoolchildren live in a municipality with a coverage rate of more than $10 \%$. In the canton of Bern, these shares correspond to $47 \%$ and $2 \%$, respectively.

Figure 1: Coverage rates of after-school care by cantons, 2010

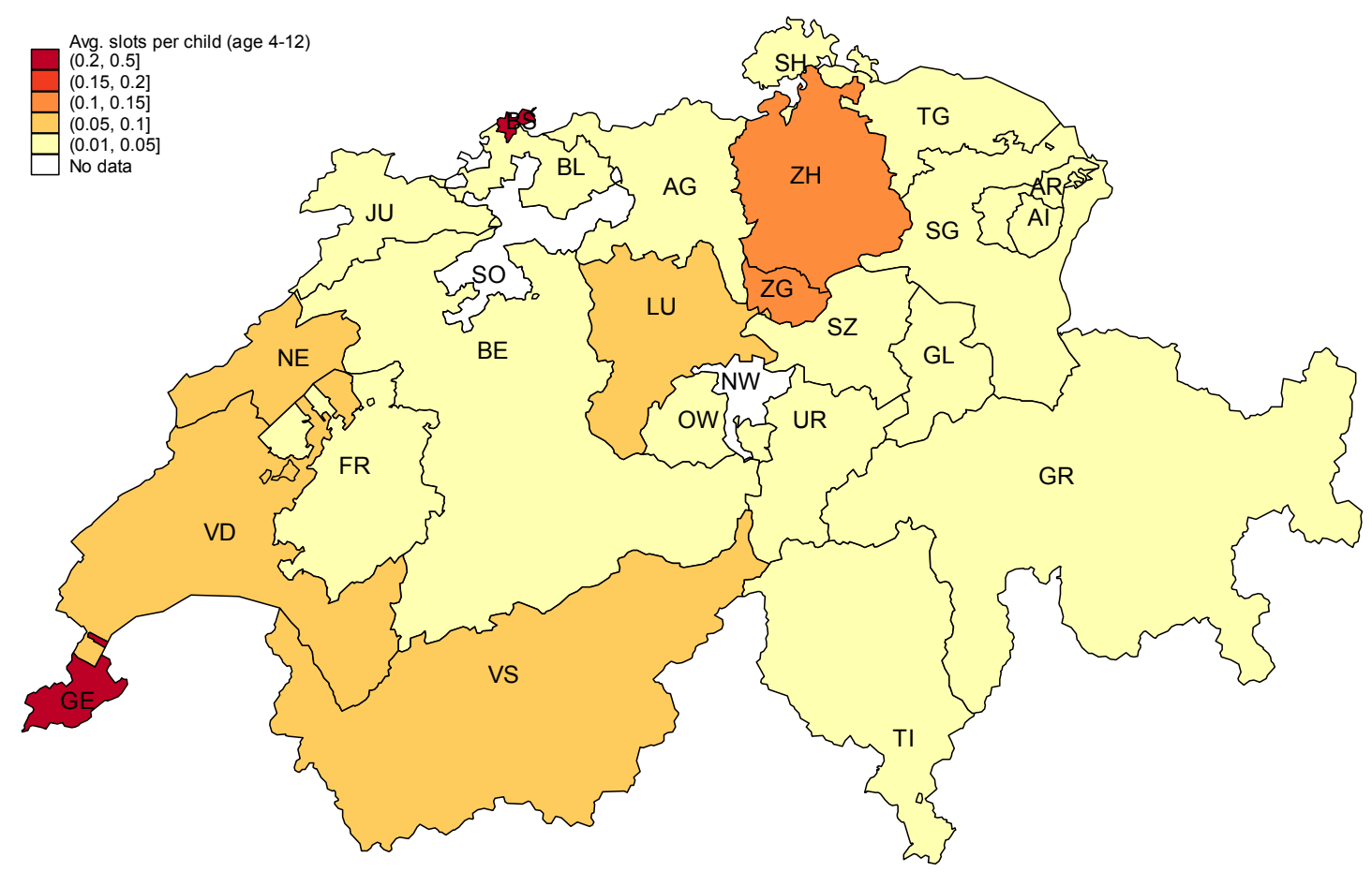

Source: Own calculations based on the 2010 population survey and childcare database. 
Figure 2: Coverage rates of after-school care by municipality in 2010

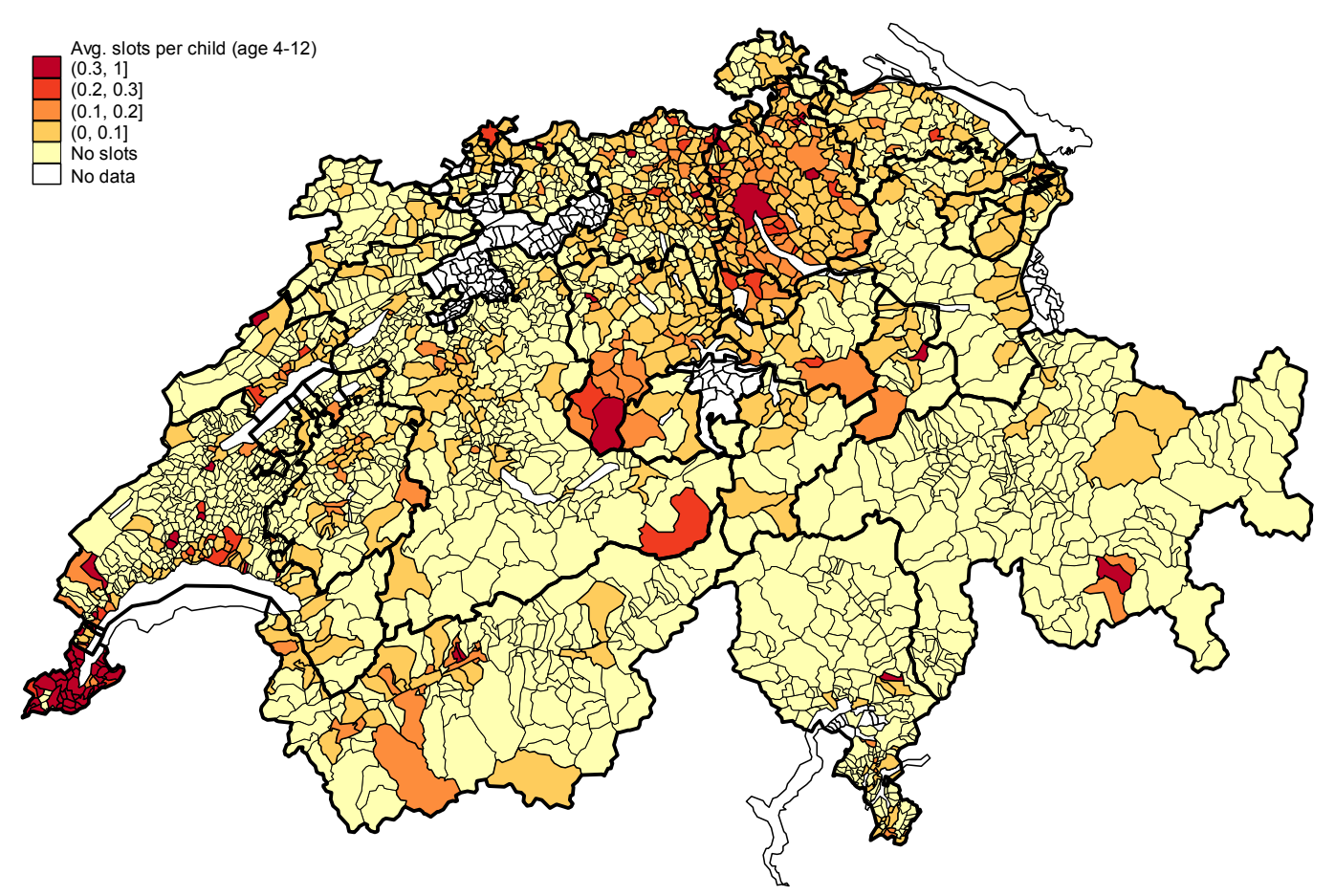

Source: Own calculations based on the 2010 population survey and childcare database.

Where do these differences come from? After a major revision of the education article in the Swiss constitution in 2006, all cantons had to revise their school laws and regulate certain elements of the education system (for example, school entrance age, and length of mandatory schooling). In light of excess demand of after-school care services and the explicit goal of the Swiss government to stimulate female participation in the labor force, several cantons used the reform of their school laws to address the gap between 
supply of and demand for after-school care services while also enforcing the provision of supplementary care for schoolchildren. ${ }^{8}$

By 2010, the year of our empirical analysis, Bern (since 2008), Solothurn (since 2007) and Zurich (since 2009) had established the enforcement of supplementary care during lunch and after-school hours. Further cantons such as Basel City, Graubünden, Lucerne, Neuchâtel, and Schaffhausen included the enforcement of the after-school care provision in their school laws after 2010. All other cantons had not established any afterschool care regulations as of 2015.

In cantons with legal enforcement, families with school-aged children enjoy a legal claim on a slot in after-school care - that is, their municipalities of residence are obliged to offer them a slot. To fulfill this requirement, the municipalities receive financial help from a federal subsidy program. The program was established just before the revision of the cantonal school laws (in 2003) and had the objective of fostering female labor supply by allowing for an easier reconciliation of work and family life. The program subsidizes new childcare facilities as well as expansions of existing childcare facilities. The subsidies cover initial fixed costs and thus enable institutions to cope with a low initial capacity utilization. The subsidies, however, were not designed for institutions to offer slots at lower prices. In fact, the increase in after-school care supply was not accompanied by a reduction in prices.

8 Note that Geneva was the first canton to enforce after-school care provisions in 1997. This legal enforcement, however, occurred long before the federal effort to harmonize the education system across cantons in 2006 and thus is not comparable (at least in the underlying motivation) to the reforms exploited within this study. 
Both public and private providers are eligible for the subsidy. ${ }^{9}$ Subsidies last for three years, and after that, the provider, which in the case of after-school care services is usually the municipality, has to ensure that the institution is self-financing. By February 2010, the program had financed 12,000 new after-school care slots; on average 9 slots per 100 schoolchildren (age 4-12) were available.

\section{$3 \quad$ Econometric framework}

\subsection{Identification}

Identifying the causal effect of after-school care provision on parents' labor supply is challenging as local supply of and demand for after-school care provision are likely to correlate with parental preferences and municipalities' efforts to attract highly qualified parents. ${ }^{10}$ We address this identification problem and exploit regional variation in the afterschool care provision that arises from differences in cantonal legislation. In a first step, we investigate the effect of cantonal regulations regarding enforcement of after-school care provisions on parental labor market outcomes ("intention-to-treat" effect). In a second step,

9 The program was launched on February 1, 2003. It is called "Federal Law on Financial Support for Extra-Familiar Childcare" ("Bundesgesetz über Finanzhilfen für familienergänzende Kinderbetreuung") and is administered by the Ministry of Social Affairs (Bundesamt für Sozialversicherung). Article 1 of the law states the purpose of the program: "The Swiss federation provides [...] childcare subsidies [...] so that parents can better reconcile family life with work and/or education" (own translation).

10 One may also think that parents may move to regions with a higher supply of childcare services. Nevertheless, Swiss citizens are rather immobile and data inspection does not reveal that changes of residence correlate with childcare provision. 
we use cantonal regulation as an instrumental variable for the local supply of after-school care.

Both strategies rely on the assumption that besides the after-school care regulations, no further differences between cantons exist that influence parental labor market outcomes directly - this is the "exclusion restriction". In other words, we assume that after-school care regulations only affect parental labor supply through the impact of regulation on the number of slots available for after-school care. For instance, if there was an impact of these regulations on the price of a slot in after-school care, the exclusion restriction would be violated; in other words, our effects would have to be interpreted as the impact of providing not only more, but also cheaper, slots in after-school care. Yet, as discussed in Section 2, there was no adjustment in prices along with the increase in supply in Switzerland. In addition, we provide evidence that any further cantonal differences are negligible (see the discussion at the end of this section as well as Table A.2 and A.3).

The instrumental variable strategy relies further on the assumption that cantonal after-school care regulations indeed influence the after-school care provision at the municipal level ("relevance" of the instrumental variable). The relevance of the instrumental variable is testable (see the results of the first stage in Section 5.1 that confirm the relevance of the instrument). The exclusion restriction, however, is more difficult to justify and unlikely to hold in general. In fact, cantonal enforcement of the after-school care provision is the outcome of a mismatch between supply and demand. As such, a difference-in-differences (DiD) approach in its classical sense - comparing parental labor supply in cantons that did and did not introduce legal enforcement of after-school care - 
likely provides biased results. A more credible approach is to restrict the analysis to confined regions along cantonal borders that represent a division in terms of after-school care regulations, in particular to economically integrated local labor markets (LLMs). We argue that regions within LLMs are not only homogenous in their employment opportunities but also in their preferences regarding after-school care services. The advantage of analyzing such a question in the context of Switzerland is that the Swiss system of direct democracy - the fact that people vote on many initiatives directly provides us with measures of people's preferences. Local results of a referendum related to family policies - to be precise, a referendum on maternity benefits in 2006 - demonstrate local views regarding the role of mothers in child rearing and thus allow us to establish homogeneity of LLMs in terms of preferences. Notice that this unique feature of Switzerland allows us to argue whether cantonal legislations may serve as an instrument for local after-school care supply within local labor markets.

We define an LLM as "integrated" if all individuals residing in an LLM have approximately the same job opportunities. Thus, for any two individuals residing in the same LLM, the cost of commuting to each potential workplace must be approximately the same. We ensure this condition by setting the maximum difference in commuting times between any pair of individuals within the same LLM to half an hour. We further assume that a maximum difference in commuting times of 30 minutes does not play a major role for the choice of workplace. Thus, for any two individuals in the same LLM, the choice of workplace should not depend on an individual's canton of residence. 
Table 1 provides details about the resulting LLMs along the borders of the canton of Bern and the canton of Zurich and their respective neighboring cantons. ${ }^{11}$ Column 1 lists the cantons that belong to the respective LLM. Column 2 displays the number of municipalities that fall into the confined regions along cantonal borders. By definition, there should be no major differences between the municipalities on opposite sides of the cantonal border in terms of commuting time to the nearest major economic hub (column 3). The average commuting time to the nearest economic hub across all municipalities amounts to about 28 minutes. People who reside on the side of the cantonal border where the after-school care provision is enforced need on average eight minutes longer to reach their nearest economic hub.

11 In principle, all border regions between the cantons of Bern, Geneva, Solothurn, Zürich and their neighbouring cantons may serve as LLMs. Nevertheless, in the French speaking part of Switzerland childcare is generally high such that cantonal enforcement does not have an effect on childcare supply. As such the cantonal border regions between Geneva and its neighboring canton (Vaud) are not included in the region under study. Moreover, we do not possess any data for the canton Solothurn. Thus, only the cantonal borders between Bern and Zurich and their neighbouring cantons are considered when creating the LLMs used in the empirical analysis. 
Table 1: Local labor markets

\begin{tabular}{|c|c|c|c|c|c|c|c|}
\hline \multirow{3}{*}{$\begin{array}{l}\text { Local } \\
\text { labor } \\
\text { market } \\
\text { (LLM) }\end{array}$} & \multirow{2}{*}{$\begin{array}{l}\text { Canton } \\
\text { (state) }\end{array}$} & \multirow{2}{*}{$\begin{array}{c}\text { \# of } \\
\text { municipalities } \\
\text { included in } \\
\text { LLM }\end{array}$} & \multirow{2}{*}{$\begin{array}{l}\text { Commuting } \\
\text { time to } \\
\text { nearest } \\
\text { economic } \\
\text { hub in } \\
\text { minutes }\end{array}$} & \multirow{2}{*}{$\begin{array}{c}\text { After- } \\
\text { school } \\
\text { care } \\
\text { (slots per } \\
100 \\
\text { children } \\
\text { age 4- } \\
12 \text { ) }\end{array}$} & \multirow{2}{*}{$\begin{array}{c}\text { Share of } \\
\text { cantonal } \\
\text { population } \\
\text { included in } \\
\text { LLM }\end{array}$} & \multicolumn{2}{|c|}{$\begin{array}{l}\text { Preferences for family } \\
\text { policies: \% votes in favor of } \\
\text { referendum }\end{array}$} \\
\hline & & & & & & $\begin{array}{l}\text { Regions } \\
\text { inside LM }\end{array}$ & $\begin{array}{l}\text { Regions } \\
\text { outside LM }\end{array}$ \\
\hline & $(1)$ & $(2)$ & (3) & (4) & $(5)$ & (6a) & (6b) \\
\hline \multirow{2}{*}{1} & $\mathrm{ZH}(\mathrm{IV}=1)$ & 13 (out of 171) & 22 & 9 & $3 \%$ & $53 \%$ & $53 \%$ \\
\hline & $\operatorname{LU}(\mathrm{IV}=0)$ & 14 (out of 87 ) & 26 & 9 & $43 \%$ & $52 \%$ & $37 \%$ \\
\hline \multirow{2}{*}{2} & $\mathrm{ZH}(\mathrm{IV}=1)$ & 24 (out of 171) & 21 & 9 & $9 \%$ & $50 \%$ & $54 \%$ \\
\hline & $A G(I V=0)$ & 60 (out of 120) & 15 & 6 & $36 \%$ & $47 \%$ & $42 \%$ \\
\hline \multirow{2}{*}{3} & $\mathrm{ZH}(\mathrm{IV}=1)$ & 60 (out of 171) & 24 & 9 & $27 \%$ & $47 \%$ & $56 \%$ \\
\hline & $A G(I V=0)$ & 40 (out of 120 ) & 19 & 7 & $27 \%$ & $49 \%$ & $42 \%$ \\
\hline \multirow{2}{*}{4} & $\mathrm{ZH}(\mathrm{IV}=1)$ & 79 (out of 171) & 34 & 11 & $23 \%$ & $50 \%$ & $55 \%$ \\
\hline & $\mathrm{SH}(\mathrm{IV}=0)$ & 25 (out of 27 ) & 18 & 3 & $99 \%$ & $47 \%$ & $27 \%$ \\
\hline \multirow{2}{*}{5} & $\mathrm{ZH}(\mathrm{IV}=1)$ & 73 (out of 171) & 34 & 8 & $15 \%$ & $46 \%$ & $55 \%$ \\
\hline & $\mathrm{TG}(\mathrm{IV}=0)$ & 28 (out of 80 ) & 25 & 3 & $36 \%$ & $40 \%$ & $39 \%$ \\
\hline \multirow{2}{*}{6} & $\mathrm{ZH}(\mathrm{IV}=1)$ & 22 (out of 171) & 36 & 7 & $6 \%$ & $48 \%$ & $54 \%$ \\
\hline & $\mathrm{TG}(\mathrm{IV}=0)$ & 49 (out of 80 ) & 22 & 4 & $59 \%$ & $41 \%$ & $37 \%$ \\
\hline \multirow{2}{*}{7} & $\mathrm{ZH}(\mathrm{IV}=1)$ & 22 (out of 171) & 36 & 7 & $6 \%$ & $48 \%$ & $54 \%$ \\
\hline & $S G(I V=0)$ & 10 (out of 85 ) & 25 & 2 & $14 \%$ & $41 \%$ & $42 \%$ \\
\hline \multirow{2}{*}{8} & $\mathrm{BE}(\mathrm{IV}=1)$ & 50 (out of 387 ) & 46 & 1 & $8 \%$ & $44 \%$ & $55 \%$ \\
\hline & $\mathrm{LU}(\mathrm{IV}=0)$ & 53 (out of 87 ) & 29 & 3 & $37 \%$ & $39 \%$ & $46 \%$ \\
\hline
\end{tabular}

Note: "IV" denotes "instrumental variable". The canton in the first line in each panel is the canton with cantonal afterschool care regulation (IV=1); the canton in the second line is the canton without after-school care regulation $(\mathrm{IV}=0)$. Note that with the exception of column (6) data only refers to the municipalities inside the respective LLM. The displayed commuting times correspond to unweighted averages over municipalities in each of the cantons. Abbreviations of cantons: AG: Aargau, BE: Bern, GR: Graubünden, TG: Thurgau, LU: Luzern, SG: St. Gallen, SH: Schaffhausen, ZH: Zürich. The nearest economic hub is defined as the respective capital of the canton (City of Zurich for ZH, City of Lucerne for LU, Aarau for AG, Schaffhausen for SH, Frauenfeld for TG, City of St. Gallen for SG, and City of Berne for BE).

Column 4 shows that the enforcement of the after-school care supply seems to be effective: municipalities in cantons that enforce the after-school care supply provide on average five slots more per 100 children. The exception is LLM 8: the municipalities that belong to Lucerne, the canton without legal enforcement of after-school care, offer on 
average three slots per 100 children, while the municipalities that belong to Bern, the canton with legal enforcement of after-school care, offer on average only one slot per 100 children.

To ensure that labor markets are sufficiently homogenous in terms of people's preferences for after-school care and thus that political choices at the cantonal level do not result from differences in preferences within the LLMs, we impose the following three conditions.

First, the population inside an LLM must not comprise the majority of any of the cantonal populations; otherwise, an LLM's population could determine cantonal laws. As column 5 shows, this condition is fulfilled, with two exceptions: in LLM 4 and 6. Yet, in both cases, it is the canton without any cantonal enforcement of the after-school care provision that does not fulfill this condition. As such, the wedge in the cantonal regulations regarding after-school care provision is caused by the remaining population of the canton that introduced the legal claim on a slot in after-school care.

Second, inside each of the LLMs, the populations belonging to different cantons must have similar preferences related to work and family. As pointed out previously, the empirical setting of Switzerland has the unique advantage of using local results of a referendum on related policies as a proxy for local preferences and thus of providing empirical evidence for the assumption underlying the exclusion restriction. Indeed, voting results on the aforementioned referendum on maternity benefits in 2006 are rather similar on both sides of the cantonal borders within each LLM (see column 6a) and therefore 
provide evidence for people residing inside an LLM to be similar in terms of the preferences related to family policies.

Third, regions outside the LLM should drive cantonal differences in legislation. Again, use the referendum on maternity benefits to provide evidence on this condition. As column $6 \mathrm{~b}$ suggests, on at least one side of the cantonal border, the remaining cantonal population outvotes the population living within the LLM. This result, in fact, highlights the likelihood of cantonal reforms to be correlated with peoples' preferences and thus should raise some caution against using a classical DiD approach without further geographic restrictions.

One possible threat to our identification strategy is that individuals with strong unobserved preferences for after-school care could move across cantonal borders within an LLM towards the enforcing canton. If this were the case, individuals who are more inclined to work would be overrepresented in the sample of cantons that enforce after-school care supply. Consequently, we would likely overestimate the effect of the childcare availability, as the policy would also support parents who would have worked even if the childcare slots were not available. To address this concern, we investigate the moving behavior of individuals across cantonal borders. Table A.1 shows the results of a probit regression. We regress a dummy variable, indicating whether the person migrated across cantonal borders within the last 12 months, on the dummy variable for cantonal enforcement and include the full set of control variables from Table 2. Our results indicate that cross-cantonal moving behavior is rare (only $1 \%$ of the people in our sample have changed cantons within the last 12 months). Moreover, no evidence for selective moves towards cantons that 
enforce the after-school care supply exists. If anything, mothers are less likely to move to such cantons.

One final concern regarding our identification strategy is potential additional differences in cantonal regulations that may affect individuals' labor supply. Such regulations may concern the tax system, the education system, or different social policies. If these regulations were different across cantons, our estimates would not isolate the effect of the availability of childcare, but rather capture the effects of various other factors as well. Table A.2 sheds light on a series of cantonal legislations and provides evidence that differences are, if they exist at all, negligible. In particular, municipalities that belong to a canton that enforces after-school care provisions offer a slight advantage in income taxes, but the amount is negligible (in all except one of the LLMs, the difference amounts to less than one percentage point, abbreviated as ppt). Only the provision of childcare slots among children between the age of zero and three is slightly lower in cantons that enforce the after-school care supply. Looking at further characteristics of the preschool system, we find few if any differences. Moreover, the minimum ages at preschool entry as well as the hours that children spend in preschool hardly differ.

\subsection{Estimation}

The empirical analysis is structured as follows: In a first set of estimations, we present an intention-to-treat effect, meaning the effect of cantonal legislations on parental labor supply. The baseline specification uses a cross-section of German-speaking LLMs in the year 2010 (see Section B.1 on details for the estimation sample). In this specification, we linearly control for all observed individual and municipality characteristics (see Section 
4, Table 2, for a list of all variables), include labor market fixed effects, and use an OLS estimator wherein we cluster standard errors on the level of cantons interacted with LLMs. The estimating equation is given by:

$$
y_{i m l c}=\gamma_{0}+\gamma_{1} I\left(\text { reform }_{c}=1\right)+X_{i}^{\prime} \gamma_{2}+W_{m}^{\prime} \gamma_{3}+D_{l}^{\prime} \gamma_{4}+\eta_{i m l c} \text {, }
$$

where $y_{i m l c}$ is the labor market outcome of individual i, I(reform f $\left._{c}=1\right)$ is an indicator variable, stating whether canton $\mathrm{c}$ is subject to a mandatory provision of afterschool care, $X_{i}$ is a vector of individual characteristics, $W_{m}$ is a vector of municipality characteristics, $D_{l}$ is a set of labor market dummy variables, and $\eta_{i m l c}$ is an idiosyncratic error term. The coefficient $\gamma_{1}$ captures the intention-to-treat effect of the reform.

To rule out unobserved cantonal differences that might confound our results for the intention-to-treat effect, we further control for unobserved cantonal differences in parental labor supply using a difference-in-differences (DiD) design; i.e., we use one available prereform year as a control period (to be more precise, the year 2000). The underlying equation is as follows:

$$
\begin{aligned}
& y_{\text {imlct }} \\
& =\rho_{0}+\rho_{1} I\left(\text { reform }_{c}=1\right)+\rho_{2} \text { Post }_{t}+\rho_{3} I\left(\text { reform }_{c}=1\right) * \text { Post }_{t}+X_{i}^{\prime} \rho_{4} \\
& +W_{m}^{\prime} \rho_{5}+D_{l}^{\prime} \rho_{6}+v_{\text {imlct }},
\end{aligned}
$$

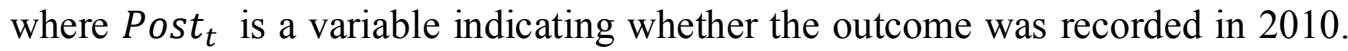
Year 2000 is the control period, for which Post $_{t}$ equals zero. In the case of the DiD we also use an OLS estimator and cluster standard errors again at the cantonal level interacted 
with the LLM. Here, the coefficient $\rho_{3}$ captures the intention-to-treat effect of the reform, accounting for unobserved differences between cantons.

In a second set of estimations, we estimate the effect of after-school care on parental employment. We rely on the cantonal regulations regarding the after-school care provision as an instrument for the after-school care supply. We use a two-stage-least-squares estimator and base our estimations again on a cross-section of German-speaking labor markets in 2010. In this case we cluster standard errors at the municipality level, as variation in the available slots occurs at this finer regional level. The main equation is given by:

$$
y_{i m l c}=\alpha_{0}+\alpha_{1} \widehat{\operatorname{slots}}_{i m l c}+X_{i}^{\prime} \alpha_{2}+W_{m}^{\prime} \alpha_{3}+D_{l}{ }^{\prime} \alpha_{4}+\eta_{i m l c},
$$

where $\widehat{\operatorname{slots}}_{i m l c}$ corresponds to the predicted number of slots per children between the ages of 4 and 12 that are available in municipality c in 2010 using the following firststage estimation:

$$
\text { slots }_{\text {imlc }}=\beta_{0}+\beta_{1} I\left(\text { reform }_{c}=1\right)+X_{i}^{\prime} \beta_{2}+W_{m}^{\prime} \beta_{3}+D_{l}^{\prime} \beta_{4}+\varepsilon_{\text {imlc }}
$$

The parameter of interest is the coefficient $\alpha_{1}$, which captures the effect of childcare supply on parental labor market outcomes.

Effect heterogeneity is a potential concern in this application, as the true effect of the after-school care provision on the parental labor supply may vary across individuals and LLMs. On the one hand, individuals' reactions to a change in available after-school care depends both on observable characteristics (e.g. education or income) and on 
unobservable characteristics (e.g. attitude towards sending their child to formal care). On the other hand, the treatment effect may vary depending on the institutional context, for example on the level of after-school care supply. In a third set of specifications, we allow for heterogeneous effects across LLMs. First, we fully interact the treatment variable with dummy variables for each LLM but still implement a two-stage-least-squares estimator. Second, we allow for effect heterogeneity across individuals and employ a semi-parametric estimation (Frölich \& Lechner, 2010). To this end, we follow the suggestions of a largescale simulation study by Huber, Lechner, and Wunsch (2013), and employ a biasadjusted-radius-propensity-score matching approach.

\section{Data}

The analysis requires information on the after-school care provision, on parents' labor supply, and on individual and regional background characteristics. Individual-level data stems from the 2010 Swiss structural survey ('Strukturerhebung 2010'). This survey supplements the 2010 Swiss Census and contains information on employment status, work hours, and socio-demographic characteristics for around 200,000 randomly selected individuals among all permanent residents who are at least 15 years old. We furthermore draw on the 2000 Swiss Census, which contains similar information, but covers the full population of Switzerland.

As the data set contains the individuals' municipalities of residence, we can merge detailed information on the availability of after-school care at the municipality level. This data comes from a newly established database that contains the number of after-school care 
slots per municipality level as of 2010. We add variables that capture the local demographic and socio-economic composition of the municipalities as well as a proxy for the municipal preferences towards family-friendly policies at the time of the reform. This proxy contains the results of a referendum related to family policies at the municipal level. The precise referendum that we rely on concerns the provision of maternity benefits in 2006 . The referendum results as well as all other regional variables are available from the Swiss Federal Statistical Office.

We restrict our sample to individuals who live in the selected LLMs (see Section B.1), are of working age (20-62 years old), and have at least one child between the ages of 4 and 12 . The resulting baseline samples correspond to 4,021 men and 4,412 women. ${ }^{12}$

The outcome variables capture parents' labor supply. We distinguish between the extensive margin - whether parents work at all - and the intensive margin - whether parents work full-time (more than 36 hours/week) or part-time (less than or equal to 36 hours/week). Table 2 provides descriptive statistics on the labor supply for the female and male samples. $70 \%$ of all women in our sample are employed. Only $10 \%$ of these women work full-time. By contrast, the majority of men work full-time (89\%). In line with our expectation that a

\footnotetext{
12 To assess the representativeness of the sample, Table A.3 in the appendix compares the population inside the LLMs with the overall population of the German-speaking area. The LLMs cover around 30\% of the German-speaking parts of Switzerland. No major differences in socio-economic and demographic characteristics between the LLMs and the complete German-speaking area exist, with the exception of the population density, which is larger outside the LLMs. This difference results from our restriction to areas that represent only a minority of the cantonal population (see Section 3). As such LLMs do not include major cities and consequently underrepresent urban areas, but represent the agglomeration and rural areas well.
} 
higher coverage rate of after-school care stimulates maternal labor supply, mothers who reside in cantons that enforce the after-school care provision are on average more likely to work at all (71\% versus $69 \%)$ and to work full-time (11\% versus $9 \%)$ than those who live in non-enforcing cantons. In contrast, men who reside in enforcing cantons are slightly more inclined to work part-time (8\% versus $7 \%)$ and slightly less inclined to work fulltime $(89 \%$ versus $90 \%)$.

Indeed, municipalities with enforcement of after-school care offer more slots (on average four slots more per hundred children) but also differ along additional dimensions. In particular, in municipalities that belong to cantons that enforce the after-school care provision, more voters supported the referendum for maternity benefits in 2004. The difference amounts to 4 ppts on average. Notice, however, the referendum did not receive a majority vote in any of these areas. Importantly, controlling for the full set of controls reduces this difference and renders it insignificant. The municipalities in cantons with enforcement of the after-school care provision are also more densely populated, have a higher share of foreigners, a higher share of commuters, a higher unemployment rate, and a lower share of homeowners.

These differences highlight that for our instrument to be valid, we must control for further regional characteristics. All estimations therefore contain the full set of individual and regional characteristics. 
Table 2: Descriptive statistics for Swiss parents, aged 21-62, with children aged 4-12

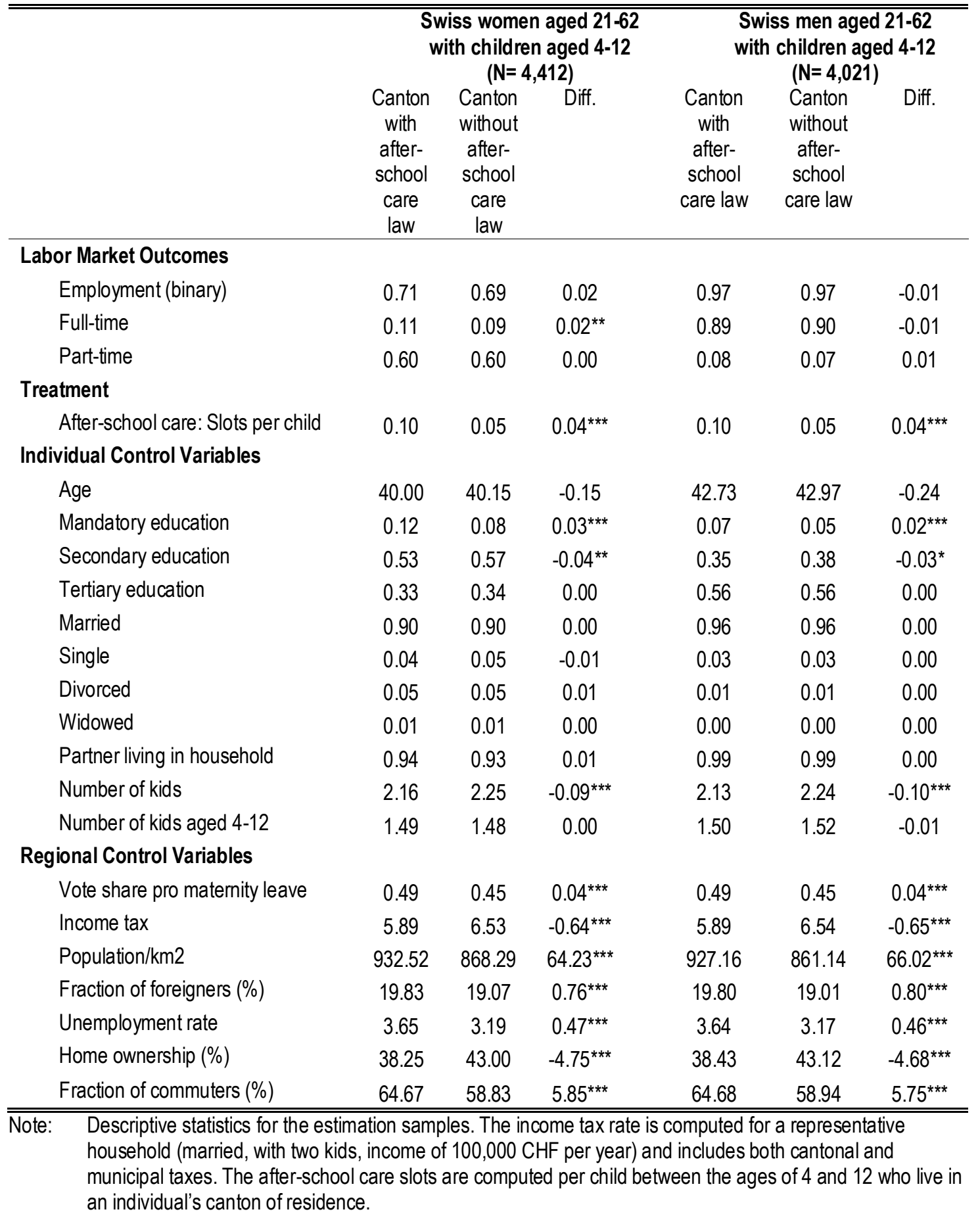




\section{$5 \quad$ Results}

\subsection{Main results}

Table 3 displays the main results for women and men with children between the ages of 4 and 12. Panel A shows the estimates of the first stage - the impact of the cantonal enforcement of the after-school care provision on the actual number of slots in after-school care - using data from the 2010 structural survey. ${ }^{13}$

Cantonal enforcement of the after-school care provision is an effective measure to increase the supply of after-school care: on average, cantonal enforcement raises the supply of after-school care by 3.6 ppts (i.e. by 3.4 slots per 100 children). Given the baseline level of five slots per 100 children, this is an increase by almost $70 \%$.

Panel B displays the reduced form estimates (intention-to-treat) of the cantonal enforcement on a set of labor supply outcomes using data from the 2010 structural survey. Overall, no statistically significant change in employment status due to cantonal enforcement exists, neither for men nor for women. Yet, cantonal enforcement of afterschool care supply leads to a statistically significant increase in women's full-time employment by 3.3 ppts. The rise in full-time employment seems to come from women who were previously working part-time: we observe a reduction in part-time employment

\footnotetext{
${ }^{13}$ The lack of data on after-school care slots in 2000 prevents us from computing the first stage estimations (and thus also the IV estimations) for the pre-treatment year 2000.
} 
by 2.7 ppts. ${ }^{14}$ It is, however, important to keep in mind that these estimates are driven by the average reaction of the (complier) population and do not allow for conclusions on the switching behavior of individuals as a reaction to the treatment (whether individuals change from no employment to part-time employment, from part-time to full-time employment, or even from no employment to full-time employment).

Panel C additionally draws on data from the 2000 Census and displays differencein-difference estimates of the reduced form. This robustness check provides evidence that any further unobservable, time-constant cantonal differences do not confound our estimates for the reduced form. The difference-in-difference estimates confirm the results of our baseline strategy (see Panel C): first, an increase in after-school care supply by 3.4 slots per 100 children induces 2.3 out of 100 women to engage in full-time employment. Second, the difference-in-difference estimates also confirm the adjustment in mothers' part-time employment. In cantons that enforce the after-school care provision, mothers decrease their part-time employment by 1.8 ppts. Analogously to the baseline estimates, we do not observe any impact on paternal labor supply, neither at the extensive nor at the intensive margin. 
Table 3: Results - Sample of parents with children aged 4-12 years

\begin{tabular}{|c|c|c|c|c|c|c|c|c|}
\hline & \multicolumn{4}{|c|}{ Women with children aged 4-12 } & \multicolumn{4}{|c|}{ Men with children aged 4-12 } \\
\hline & Estimate & $\begin{array}{c}\text { S.E. } \\
\text { (analytic) }\end{array}$ & $\begin{array}{l}\text { p-value } \\
\text { (analytic) }\end{array}$ & $\begin{array}{c}\text { p-value } \\
\text { (wild } \\
\text { bootstrap) }\end{array}$ & Estimate & $\begin{array}{c}\text { S.E. } \\
\text { (analytic) }\end{array}$ & $\begin{array}{l}\text { p-value } \\
\text { (analytic) }\end{array}$ & $\begin{array}{l}\text { p-value } \\
\text { (wild } \\
\text { bootstrap) }\end{array}$ \\
\hline \multicolumn{9}{|c|}{ Panel A. First Stage 2010 (Effect of cantonal enforcement on slots per child) } \\
\hline Slots & 0.036 & 0.011 & 0.005 & 0.048 & 0.035 & 0.011 & 0.006 & 0.066 \\
\hline
\end{tabular}

Panel B: Intention-to-Treat/Reduced Form 2010 (Effect of cantonal enforcement on labor supply)

\begin{tabular}{ccccc|cccc} 
Employed & 0.006 & 0.021 & 0.773 & 0.768 & 0.006 & 0.008 & 0.473 & 0.620 \\
Full time & 0.033 & 0.017 & 0.068 & 0.074 & -0.001 & 0.009 & 0.924 & 0.936 \\
Part time & -0.027 & 0.015 & 0.084 & 0.072 & 0.007 & 0.013 & 0.621 & 0.730
\end{tabular}

Panel C: Intention-to-Treat/Difference-in-Difference, 2010 vs. 2000 (Effect of cantonal enforcement on labor supply)

\begin{tabular}{ccccc|cccc}
\hline Employed & 0.005 & 0.013 & 0.689 & 0.718 & -0.005 & 0.004 & 0.298 & 0.384 \\
Full time & 0.023 & 0.011 & 0.060 & 0.074 & -0.012 & 0.009 & 0.202 & 0.282 \\
Part time & -0.018 & 0.009 & 0.063 & 0.096 & 0.007 & 0.010 & 0.476 & 0.534
\end{tabular}

Panel D: Instrumental Variables (Effect of slots per child on labor supply, instrumental variable: cantonal enforcement)

\begin{tabular}{ccccc|cccc} 
Employed & 0.169 & 0.752 & 0.822 & - & 0.167 & 0.267 & 0.532 & - \\
Full time & 0.912 & 0.560 & 0.103 & - & -0.026 & 0.404 & 0.948 & - \\
Part time & -0.743 & 0.816 & 0.362 & - & 0.193 & 0.392 & 0.622 & -
\end{tabular}

\footnotetext{
Note: The results are based on the sample of parents between the ages of 20 and 62 with at least one child in the 4-to-12 age range. In all specifications, we control for all individual and municipality characteristics from Table 2 and include labor market fixed effects. Age is included in the form of dummy variables (five-year age categories). Panels A, B, and D are based on 4,412 observations for females and 4,021 observations for males and are obtained using OLS estimation and clustering at LM-by-canton level (16 clusters). We report analytic standard errors and p-values as well as wild bootstrap p-values (to account for the low number of clusters). The estimates in Panel $D$ are obtained using the same sample but using two-stage-least-squares estimators and clustering at the municipality level (274 clusters). The difference-in-difference estimates in Panel $C$ use the year 2000 as the baseline period and the year 2010 as the treatment period. Estimates stem from OLS regressions clustering at the cantonal level interacted with the LLM and are based on 61,772 observations for females and on 58,178 observations for males. ${ }^{* *} p$-value $<0.01,{ }^{* *}$-value $<0.05,{ }^{*} p$ value $<0.1$.
}

The instrumental-variable estimates allow us to assess the elasticity of parental employment with respect to the after-school care supply (see Panel D). In line with the 
reduced form estimates, we observe a strong, albeit statistically insignificant, reaction for mothers' work hours. There is again no comparable effect for fathers. To be more precise, an increase in after-school care coverage by 1 ppt leads to an increase in maternal full-time employment by 0.9 ppts. In other words, every newly created after-school care slot allows almost one more mother to work full-time.

Our estimate for the elasticity of mothers' full-time labor supply with respect to childcare provision is sizeable compared to the results of previous studies. We would therefore like to stress the differences between our setting and the setting of previous studies. First, our study does not focus on preschool children, as most previous studies do, but instead focuses on schoolchildren. These children already go to school every day. Thus, the decision to send them to after-school care does not involve parents' first-time decision to place their children in childcare and thus might reflect less hesitation towards using such an institution. Second, in line with previous studies, we do not observe any finding at the extensive margin. Our results refer only to the intensive margin, which the previous literature has barely considered. Finally, our estimates reflect the effects of an increase in after-school care in a setting where childcare is scarce. Our estimates may not generalize to a setting with an already high supply of childcare.

\subsection{Sensitivity analysis}

The positive effects of the after-school care supply on female full-time employment are largely robust to the choice of a more flexible specification. In the following robustness checks, we allow for heterogeneity across LLMs as well as for non-linear influences of the

control variables on the outcome. As a benchmark, Table 4, Panel A reports the results of 
the instrumental variables estimations, which are identical to the ones reported in Table 3 , Panel D.

Panel B reports the results of a parametric specification that allows for heterogeneity across labor markets. We fully interact the treatment variable with dummy variables for each LLM and then aggregate the coefficients over all LLMs. Again, we linearly control for all covariates from Table 2 and cluster at the municipal level. The results show little heterogeneity in maternal responses across the different labor markets. Signs and magnitudes barely differ between Tables 2 and 3 for mothers, but do diverge more for fathers. Overall, the imprecision of the estimates in Panel B may account for the difference of the results for fathers between Panels A and B. 
Table 4: Sensitivity analysis of the instrumental variable (IV) estimates



Panel C presents the results from a non-parametric instrumental variable approach.

The non-parametric estimator consists of two propensity-score matching estimators - the matching estimator for the reduced form, divided by the matching estimator for the first stage. As such we need both a binary instrumental variable and a binary treatment variable. Thus, we discretize the treatment and define a municipality as treated if its level of childcare coverage lies above the LLM-specific median. Based on this discretization, 
treated (high-supply) municipalities offer on average 11 slots per 100 children whereas control (low-supply) municipalities offer on average three slots per 100 children; therefore, treated municipalities supply on average eight slots more per 100 children. The propensity scores incorporate a subset of the control variables from Table 2. The reason for this is the data intensity of the approach (see Table 4 for details).

The positive effect on female full-time employment is also robust with respect to this non-parametric specification. In order to compare Panel C with Panels A and B, we divide the estimates from Panel $\mathrm{C}$ by 0.08 , which is the average difference in childcare coverage between treated and control municipalities. Thus, according to Panel $\mathrm{C}$, one additional childcare slot allows one additional mother to work full-time. By contrast, the results on the extensive margin and on part-time employment, as well as the results for fathers, do not match the estimates reported in Panels A and B. We attribute these disparities both to the differences in the specification and to the lack of important control variables in the non-parametric matching approach.

\section{Conclusion}

This paper addresses the question of whether after-school care provision can affect parental labor supply. The analysis relies on cantonal regulations in the after-school care provision as instrumental variables for the after-school care supply at the municipality level. To establish exogeneity of cantonal regulations with respect to employment opportunities and preferences of the population, we restrict our analysis to confined regions along cantonal borders. Using data from the 2000 and 2010 Swiss Census, we find that 
after-school care provision does not stimulate overall employment, but it does increase fulltime employment for mothers. We find no comparable effect for fathers.

Many developed countries are considering an expansion of their childcare systems. Besides care provision for preschool children, supplementary care for schoolchildren has received increased attention. Switzerland, for example, launched a federal program in 2003 to provide subsidies to new or expanding care institutions. Germany is currently in the process of extending its school system and offering an increasing number of all-day schools. Regarding maternal employment and female career opportunities, this investment might pay off: our results indicate that each newly created after-school care slot enables one more mother to work full-time. Yet, one has to bear in mind that our findings apply to a setting with very low levels of after-school care and may not generalize to settings with rather high after-school care supply. To compare high- and low-supply settings and allow for predictions regarding the impact of after-school care on paternal employment at different levels of supply, more research is needed.

\section{Bibliography}

Baker, M., Gruber, J., \& Milligan, K. (2008). Universal Childcare, Maternal Labor Supply, and Family Well-being. Journal of Political Economy, 116(4), 709-745.

Berlinski, S., \& Galiani, S. (2007). The effect of a large expansion of pre-primary school facilities on preschool attendance and maternal employment. Labour Economics, 14(3), 665-680. 
Black, S. (1999). Do Better Schools Matter? Parental Valuation of Elementary Education.

Quarterly Journal of Economics, 114, 577-599.

Blau, D., \& Currie, J. (2006). Pre-School, Day Care, and After-School Care: Who's Minding the Kids? In E. Hanushek, \& F. Welch (Eds.), Handbook of the Economics of Education (Vol. 2, pp. 1163-1278). Elsevier.

Blau, D., \& Robins, P. (1988). Child-care costs and family labor supply. The Review of Economics and Statistics, 70(3), 374-381.

Bratti, M., Bono, E. D., \& Vuri, D. (2004). New mothers' labour force participation in Italy: The role of job characteristcis. Labour, 19:79-121.

Card, D., \& Krueger, A. (1994). Minimum Wages and Employment: A Case Study of the FastFood Industry in New Jersey and Pennsylvania. American Economic Review, 84, 772793.

Cascio, E. (2009). Maternal Labor Supply and the Introduction of Kindergartens into American Public Schools. Journal of Human Resources, 74, 140-170.

Connelly, R. (1992). The Effect of Child Care Costs on Married Women's Labor Force Participation. The Review of Economics and Statistics, 74(1), 83-90.

Currie, J., \& Moretti, E. (2003). Mothers' Education and the Intergenerational Transmission of Human Capital: Evidence from College Openings. Quarterly Journal of Economics, $118(4), 1495-1532$. 
Felfe. (2012). The motherhood wage gap: What about job amenities. Labour Economics, 19(1):59-67.

Felfe, C. (2015). Childcare and Child Development. CESifo DICE Report, 13 (1): 16-19.

Felfe, C., Lechner, M., Iten, R., Schwab, S., Stern, S., \& Thiemann, P. (2013).

Familienergänzende Kinderbetreuung und Gleichstellung. Bern: Schweizer Nationalfond.

Fitzpatrick, M. (2010). Preschoolers Enrolled and Mothers at Work? The Effects of Universal Pre-Kindergarten. Journal of Labour Economics, 28(1):51-85.

Fitzpatrick, M. (2012). Revising Our Thinking about the Relationship between Maternal Labor Supply and Preschool. Journal of Human Resources, 47, 583-612.

Frölich, M. (2007). Nonparametric IV estimation of local average treatment effects with covariates. Journal of Econometrics, 139: 35-75.

Frölich, M., \& Lechner, M. (2010). Exploiting Regional Treatment Intensity for the Evaluation of Labour Market Policies. Journal of American Statistical Association, 105(491), 10141029.

FSIO. (2010). Financial Support for Extra-Familiar Childcare: Results after 7 Years. Retrieved March 31, 2014, from http://www.bsv.admin.ch/praxis/kinderbetreuung/00112/

Gelbach, J. (2002). Public schooling for young children and maternal labor supply. The American Economic Review, 92(1), 307-322. 
Geyer, J., Haan, P. \& Wrolich, K. (2015). The effects of family policy on maternal labor supply: Combining evidence from a structural model and a quasi-experimental approach. Labour Economics, 36:84-98

Goux, D., \& Maurin, E. (2010). Public school availability for two-year olds and mothers' labour supply. Labour Economics, 17(6), 951-962.

Havnes, T., \& Mogstad, M. (2011). Money for Nothing? Universal Child Care and Maternal Employment. Journal of Public Economics, 95(11-12), 1455-1465.

Holmes, T. (1998). The Effect of State Policies on the Location of Manufacturing: Evidence from State Borders. Journal of Political Economy, 106, 667-705.

Huber, M., Lechner, M., \& Wunsch, C. (2013). The Performance of Estimators Based on the Propensity Score. Journal of Econometrics, (175): 1-21.

Imbens, G. W., \& Wooldridge, J. M. (2009). Recent Developments in the Econometrics of Program Evaluation. Journal of Economic Literature, 47(1), 5-86.

Imbens, G., \& Angrist, J. (1994). Identification and estimation of local average treatment effects. Econometrica, 62(2), 467-475.

Kamette, F. (2011). Organisation of School Time in the European Union. Fondation Robert Schumann, Policy Paper, 212.

Kimmel, J. (1998). Child care costs as a barrier to employment for single and married mothers. Review of Economics and Statistics, 80(2), 287-299. 
Lefebvre, P., \& Merrigan, P. (2008). Childcare Policy and the Labor Supply of Mothers with Young Children: A Natural Experiment from Canada. Journal of Labor Economics, 23(3), 519-548.

Lundin, D., Mörk, E., \& Öckert, B. (2008). How far can reduced childcare prices push female labour supply? Labour Economics, 15(4), 647-659.

Michalopoulos, C., Robins, P., \& Garfinkel, I. (1992). A structural model of labor supply and child care demand. Journal of Human Resources, 27(1), 166-203.

Moretti, E. (2004). Workers' Education, Spillover, and Productivity: Evidence from Plant-Level Production Functions. American Economic Review, 3(94), 656-691.

Nollenberger, N., \& Rodriguez-Planas, N. (2015), Full-time universal childcare in a context of low maternal employment: Quasi-experimental evidence from Spain, Labour Economics 36: $124-136$.

OECD. (2001). OECD Employment Outlook. Retrieved March 31, 2014, from http://www.oecdilibrary.org/content/book/empl_outlook-2001-en

OECD Family Database. (2012). Retrieved September 9, 2013, from www.oecd.org/social/family/database

Pence, K. (2006). Foreclosing on Opportunity: State Laws and Mortgage Credit. Review of Economics and Statistics, 88, 177-182.

Schlosser, A. (2011). Public Preschool and the Labor Supply of Arab Mothers: Evidence from a Natural Experiment. mimeo. 
Waldfogel, J. (1997). The effect of children on women's wages. American Sociological Review,

62: 209-217.

\section{Appendix A}

Table A.1: Migration into cantons with enforcement of after-school care

Dependent variable: Migration across cantons within the past 12 months (binary)

\begin{tabular}{|c|c|c|c|c|}
\hline & \multicolumn{2}{|c|}{ Females } & \multicolumn{2}{|c|}{ Males } \\
\hline & Marg. Eff. & S.E. & Marg. Eff. & S.E. \\
\hline Enforcement (instrument) & $-0.014^{* *}$ & 0.007 & -0.010 & 0.006 \\
\hline Individual controls & \multicolumn{2}{|c|}{ Yes } & \multicolumn{2}{|c|}{ Yes } \\
\hline Municipality controls & \multicolumn{2}{|c|}{ Yes } & \multicolumn{2}{|c|}{ Yes } \\
\hline Labor market fixed effects & \multicolumn{2}{|c|}{ Yes } & \multicolumn{2}{|c|}{ Yes } \\
\hline Baseline probability & \multicolumn{2}{|c|}{0.010} & \multicolumn{2}{|c|}{0.011} \\
\hline Pseudo-R2 & \multicolumn{2}{|c|}{0.074} & \multicolumn{2}{|c|}{0.065} \\
\hline Number of observations & \multicolumn{2}{|c|}{4,412} & \multicolumn{2}{|c|}{4,021} \\
\hline
\end{tabular}

Note: The table shows average marginal effects from probit regressions. The dependent variable is 1 if the individual migrated from a different canton or from abroad within the past 12 months before the survey. Estimates are based on the estimation sample (males and females between the ages of 21 and 62 with at least one child in the 4-12 age range). In all regressions, we control for all control variables from Table $2 .{ }^{* * *} p<0.01,{ }^{* *} p<0.05$, * $p<0.1$. 
Table A.2: Institutions: Preschool, childcare for younger children, elderly care, taxes

\begin{tabular}{|c|c|c|c|c|c|}
\hline $\begin{array}{l}\text { Local } \\
\text { labor } \\
\text { market }\end{array}$ & Canton & $\begin{array}{c}\text { Childcare } \\
\text { slots per } \\
100 \\
\text { children } \\
0-3\end{array}$ & $\begin{array}{l}\text { Minimum } \\
\text { age at } \\
\text { preschool } \\
\text { entry }\end{array}$ & $\begin{array}{l}\text { Preschool: } \\
\text { hours per } \\
\text { week (last } \\
\text { preschool } \\
\text { year) }\end{array}$ & Median tax \\
\hline & (1) & (2) & (3) & (4) & (5) \\
\hline \multirow[t]{2}{*}{1} & $\mathrm{ZH}(\mathrm{IV}=1)$ & 8 & 4 yr. 3 m. & $21-23$ & 5.9 \\
\hline & LU $(I V=0)$ & 15 & 4 yr. 9 m. & $15-18$ & 7.3 \\
\hline \multirow[t]{2}{*}{2} & $\mathrm{ZH}(\mathrm{IV}=1)$ & 8 & 4 yr. 3 m. & $21-23$ & 5.9 \\
\hline & $A G(I V=0)$ & 12 & 4 yr. 3 m. & $21-25$ & 6.3 \\
\hline \multirow[t]{2}{*}{3} & $\mathrm{ZH}(\mathrm{IV}=1)$ & 9 & 4 yr. $3 \mathrm{~m}$. & $21-23$ & 5.9 \\
\hline & $A G(I V=0)$ & 13 & 4 yr. 3 m. & $21-25$ & 6.2 \\
\hline \multirow[t]{2}{*}{4} & $\mathrm{ZH}(\mathrm{IV}=1)$ & 9 & 4 yr. 3 m. & $21-23$ & 6 \\
\hline & $\mathrm{SH}(\mathrm{IV}=0)$ & 17 & 4 yr. 3 m. & 20.4 & 6.6 \\
\hline \multirow[t]{2}{*}{5} & $\mathrm{ZH}(\mathrm{IV}=1)$ & 5 & 4 yr. 3 m. & $21-23$ & 6 \\
\hline & $\mathrm{TG}(\mathrm{IV}=0)$ & 8 & 4 yr. 3 m. & $21-25$ & 7 \\
\hline \multirow[t]{2}{*}{6} & $\mathrm{ZH}(\mathrm{IV}=1)$ & 6 & 4 yr. 3 m. & $21-23$ & 6 \\
\hline & $\mathrm{TG}(\mathrm{IV}=0)$ & 8 & 4 yr. 3 m. & $21-25$ & 6.8 \\
\hline \multirow[t]{2}{*}{7} & $\mathrm{ZH}(\mathrm{IV}=1)$ & 6 & 4 yr. $3 \mathrm{~m}$. & $21-23$ & 6 \\
\hline & $S G(I V=0)$ & 5 & $4 \mathrm{yr}$. & 24 & 6 \\
\hline \multirow[t]{2}{*}{8} & $\mathrm{BE}(\mathrm{IV}=1)$ & 5 & 4 yr. $3 \mathrm{~m}$. & $16.5-19.5$ & 8.8 \\
\hline & $\mathrm{LU}(\mathrm{IV}=0)$ & 2 & 4 yr. 9 m. & $15-18$ & 7.8 \\
\hline
\end{tabular}

Note: The income tax rate is computed for a representative household (married, with two kids, income of 100,000 $\mathrm{CHF}$ per year) and includes both cantonal and municipal taxes. Averages and medians are unweighted. ${ }^{*}$ Fraction is computed with respect to all children in their first year of primary school. ${ }^{* *}$ Introduced: 2010 2013. Abbreviations of cantons: AG: Aargau, BE: Bern, GR: Graubünden, TG: Thurgau, LU: Luzern, SG: St. Gallen, SH: Schaffhausen, ZH: Zürich. Information for school institutions is for school year 2009/10. Childcare slots per 100 children aged zero to three are reported for areas inside the local labor markets only. 
Table A.3: Descriptive statistics - Representativeness of the local labor markets for the German-speaking part of Switzerland

\begin{tabular}{|c|c|c|c|c|}
\hline & \multirow{2}{*}{$\begin{array}{c}\text { Local labor } \\
\text { markets } \\
(\text { LLMs) } \\
\text { Mean }\end{array}$} & \multirow{2}{*}{$\begin{array}{c}\text { German-speaking } \\
\text { Switzerland } \\
\text { Mean }\end{array}$} & \multicolumn{2}{|c|}{$\begin{array}{c}\text { LLMs- } \\
\text { German-speaking Switzerland }\end{array}$} \\
\hline & & & Difference & p-val. \\
\hline \multicolumn{5}{|l|}{ Labor Market Outcomes } \\
\hline Employment (binary) & 0.83 & 0.83 & -0.01 & 0.195 \\
\hline Full time & 0.48 & 0.47 & 0.01 & 0.328 \\
\hline Part time & 0.35 & 0.36 & -0.01 & 0.043 \\
\hline \multicolumn{5}{|l|}{ Treatment/Instrument } \\
\hline After-school care: Slots per child & 0.06 & 0.08 & -0.02 & 0.000 \\
\hline Reform canton (binary) & 0.32 & 0.42 & -0.10 & 0.000 \\
\hline \multicolumn{5}{|l|}{ Individual Control Variables } \\
\hline Female & 0.52 & 0.52 & 0.00 & 0.792 \\
\hline Age & 41.35 & 41.43 & -0.09 & 0.183 \\
\hline Mandatory education & 0.08 & 0.09 & -0.01 & 0.000 \\
\hline Secondary education & 0.49 & 0.46 & 0.03 & 0.000 \\
\hline Tertiary education & 0.42 & 0.44 & -0.02 & 0.001 \\
\hline Married & 0.93 & 0.93 & 0.00 & 0.707 \\
\hline Single & 0.03 & 0.03 & 0.00 & 0.447 \\
\hline Divorced & 0.03 & 0.03 & 0.00 & 0.633 \\
\hline Widowed & 0.01 & 0.00 & 0.00 & 0.047 \\
\hline Partner living in household & 0.96 & 0.96 & 0.00 & 0.050 \\
\hline Number of kids & 2.26 & 2.25 & 0.01 & 0.335 \\
\hline Number of kids aged 4-12 & 1.51 & 1.50 & 0.01 & 0.129 \\
\hline \multicolumn{5}{|l|}{ Regional control variables } \\
\hline Vote share pro matemity leave & 0.45 & 0.48 & -0.03 & 0.000 \\
\hline Income tax rate & 6.62 & 6.61 & 0.01 & 0.506 \\
\hline Population/km2 & 771 & 1286 & -515 & 0.000 \\
\hline Fraction of foreigners (\%) & 17.65 & 18.61 & -0.96 & 0.000 \\
\hline Unemployment rate & 3.09 & 3.05 & 0.04 & 0.002 \\
\hline Home ownership (\%) & 42.57 & 37.75 & 4.83 & 0.000 \\
\hline Fraction of commuters (\%) & 59.47 & 51.38 & 8.09 & 0.000 \\
\hline
\end{tabular}

Note: Sample: German-language region, males and females between the ages of 21 and 62 with at least one child in the age range of $4-12(n=35,508)$. 10,642 individuals live inside a local labor market (LLM), 24,866 individuals live outside a local labor market. The income tax rate is computed for a representative household (married, with two kids, income of 100,000 CHF per year) and includes both cantonal and municipal taxes. 


\section{Appendix B}

\section{B.1 Construction of local labor markets}

To construct local labor markets (LLMs), we draw upon the 160 Swiss "Mobilité Spatiale regions" (henceforth "MS regions"), which were defined in 1982 by the statistical office of Switzerland based on commuting behavior. We combine all MS regions that lie within a limited commuting area (30 minutes by car) and that lie along a cantonal border that signifies a division in the cantonal regulation of after-school care services. ${ }^{15} \mathrm{We}$ drop all LLMs i) where the area on one side of the cantonal border contains the majority of the respective cantonal population; ${ }^{16}$ ii) where the populations on both sides of the cantonal border differ strongly in their preferences related to work and family; and iii) where no clear division exists in the preferences related to work and family between the municipalities inside and outside the LLM in at least one of the two cantons considered in the respective LLM. Section B.2 provides empirical evidence for these restrictions.

The resulting LLMs are either municipalities at the cantonal division of Bern with the surrounding cantons (here, Lucerne) or municipalities at the cantonal division of Zurich

15 Note that LLMs can overlap. Yet we only consider LLMs that contain exactly one cantonal border, i.e. that contain municipalities from exactly two different cantons.

16 We deviate twice from this condition, in LLM 5 and in LLM 7, but the discontinuity regarding the cantonal legislation and thus the after-school care provision across the cantonal border is in both cases driven by the other cantonal part. In other words, there is at least one cantonal part where the population living inside the LLM is outvoted by the population living outside the LLM. 
with the surrounding cantons (Aargau, Lucerne, Schaffhausen, St. Gallen, and Thurgau). ${ }^{17}$

Figure B.1 represents the geographical area covered by the LLMs. Although the geographical area is rather small, it contains $20 \%$ of the overall Swiss population (and $30 \%$ of the overall German-speaking population of Switzerland).

17 There are two further potential sets of cantonal borders: borders of the canton Solothurn and its neighbor cantons, and borders between the cantons Geneva and Vaud. Because of the lack of data on after-school care for Solothurn, we cannot use any LLM based on Solothurn and the neighboring cantons. The LLM along the cantonal border between Geneva and Vaud cannot be used for our analysis either as there is no strong heterogeneity in the preferences regarding work and family within the respective cantons. One further potential LLM stretching over the cantonal border between Zurich and Zug is excluded as income taxes, an issue discussed in Section 5.2, are substantially different between cantons. 




Source: Own calculations.

\section{B.2 Empirical evidence for the conditions imposed on local labor markets}

Table 1 lists the resulting LLMs. Bern and Zurich are cantons that by 2010 (the year of our data) explicitly enforce after-school care - thus, the observations that belong to these cantons are assigned the value "one" for the IV. The remaining cantons Aargau, Lucerne, Schaffhausen, St. Gallen, and Thurgau, did not explicitly enforce after-school care in their cantonal legislation by 2010 - therefore observations belonging to these cantons are assigned the value "zero" for the IV.

Table 1 in the main text, column 4, provides descriptive evidence for strong IVs and the cantonal borders to be monotone. Cantonal laws enforcing after-school care indeed 
correlate positively with the after-school care provision. With the exception of one LLM (LLM 8), there is a higher supply of after-school care in the municipalities of the canton legally enforcing the after-school care provision than in the municipalities of the canton not legally enforcing the after-school care provision. ${ }^{18}$

Table 1, columns 5-6, provides some supportive evidence that the cantonal school law is exogenous to the preferences related to work and family of the population residing in municipalities within the LLM. First, the municipalities included in the LLMs correspond on at least one side of the cantonal border to the minority of the respective cantonal population. Second, the populations to both sides of the cantonal border share the same preferences regarding work and family. To address this issue, we rely on the results of the referendum on maternity benefits (held September 26, 2004). Results on the referendum are rather similar across the cantonal border within each LLM. Yet, on at least one side of the cantonal border, the remaining cantonal population outside the LLM outvotes the population living inside the LLM.

Using the example of the LLM along the cantonal border between Bern and Lucerne helps to illustrate this issue. Inside the LLM, the referendum failed on both sides of the cantonal border. It also failed in the remaining municipalities of the canton Lucerne. However, the respective municipalities belonging to the canton Bern were outvoted by the

\footnotetext{
18 When aggregating the estimates for the different LLMs, we weight each estimate by the number of compliers inside the respective LLM and thus, any defiers - municipalities that decrease their after-school care because of the legal enforcement - are not taken into consideration.
} 
remaining cantonal population. Hence, while citizens inside the LLM are rather similar regarding their preferences relating to work and family, the remaining cantonal population outside the LLM differs, in at least one of the two cantons, strongly with respect to such preferences. As a result, differences in the existing cantonal laws related to work and family might arise but are unlikely to be driven by the population living in the municipalities belonging to the LLM.

\section{Appendix C: Technical Appendix}

This appendix contains information on the semi-parametric specification as reported in Section 5.2, Table 4 .

The semi-parametric instrumental variable strategy requires both a binary instrumental variable (indicator whether a canton enforces labor supply) and a binary treatment variable that captures the childcare availability. We therefore discretize the treatment variable and define a municipality as having "high childcare coverage" if the after-school care availability in this municipality lies above the LLM-specific median, or otherwise has "low childcare coverage".

The corresponding parameter of interest is the local average treatment effect (LATE), which is the effect of high childcare coverage on individuals living in "complier municipalities" (Imbens \& Angrist, 1994). Complier municipalities are those municipalities whose coverage is high if and only if their canton enforces childcare supply. 
The estimation proceeds in two steps. First, we estimate the LATE for each LLM separately ("within-LLM IV"). Second, we aggregate the effect over all LLMs. The first step accounts for effect heterogeneity across local labor markets. The second step increases the precision of the estimates. Effect heterogeneity is an important concern in this application, as the true effect of the after-school care provision on the parental labor supply may vary across individuals and LLMs. On the one hand, individuals' reactions to a change in after-school care availability depends both on observable characteristics (i.e. education or income) and on unobservable characteristics (i.e. attitude towards sending children to formal care). On the other hand, the treatment effect may vary depending on the institutional context. For instance, depending on the level of after-school care supply, different types of individuals might decide to use after-school care. Since the level of afterschool care supply varies strongly across LLMs (see Table 1, column 6), treatment effects are most likely heterogeneous in our application.

The within-LLM IV estimator combines the estimation approach by Frölich (2007), which extends the LATE framework by Imbens and Angrist (1994) to allow for control variables by matching on the propensity score, with the findings of a large-scale simulation study by Huber, Lechner, and Wunsch (2013). The estimator corresponds to a ratio of two matching estimators - that is, the effect of the instrument on the outcome is divided by the effect of the instrument on the treatment. ${ }^{19}$ Since this method relies on a binary treatment,

19 To compute the two matching estimators we use the bias-adjusted-radius-propensity-score matching approach. This estimator uses a parametric propensity score to remove the effect of observable confounders that might jeopardize the validity of the instrument. By using a parametric (probit) model for the link between instruments and instrument 
we define a cut-off that categorizes municipalities in areas with relatively high after-school care coverage - treated municipalities - and areas with relatively low after-school care coverage - control municipalities. Given the high variation in after-school care coverage between LLMs (see Table 1, column 6), a single cut-off for all LLMs would result in a rather unequal distribution of treated and control areas within LLMs. We therefore define separate cut-offs for each LLM. The LLM-specific median as cut-off guarantees a similar number of treated and control observations in each LLM. The resulting cut-off coverage rates vary between $0.4 \%$ and $8.1 \%$ (see Table A.2). The difference between the average care coverage in municipalities below and equal to the cut-off and the average care coverage in municipalities above the cut-off - the treatment intensity - amounts to 8 ppts on average, but varies across LLMs (between 5 and 11 ppts, see Table A.2).

After estimating the effects for each LLM separately, we aggregate the different effects to increase precision. Since the IV estimates are the effects for "compliers" - that is, the effects for individuals living in "complier municipalities" (see Section 3.1) - our preferred weighting scheme is based on the number of compliers in the respective LLM. ${ }^{20}$ In addition, we propose three alternative weighting schemes based on the following populations: first, based on the number of compliers, but using only those LLMs where the

confounders only, and being otherw ise fully nonparametric, such estimators avoid the 'curse of dimensionality' which is inherent to all non-parametric procedures, but at the same time retain most of their flexibility. The results on the probit estimations for each LLM are shown in Table I.2 in the Internet appendix.

${ }^{20}$ Estimated by the denominator of the IV estimator times the number of observations. 
estimates are within the logical range (where the effect of cantonal enforcement on childcare coverage is positive); second, based on the number of observations of the respective LLM; and third, based on the number of observations, but using only those LLMs for which the estimates are within the logical range. Inference is based on bootstrapping and the quantile method: bootstrapping the effects and considering their distribution to obtain significance levels. We implement the bootstrap as a block bootstrap taking into account the possible correlation of individuals within the same municipality. 